\title{
Effects of pedagogical movie Persian subtitles on vocabulary improvement: The case of Iranian EFL learners
}

\author{
Roya Rostam Shirazi ${ }^{1}$, Akbar Hesabi $^{2}$, Shahla Simin ${ }^{3}$ \\ ${ }^{1}$ English Department, Najafabad Branch, Islamic Azad University, Najafabad, Iran \\ ${ }^{2}$ University of Isfahan, Isfahan, Iran \\ ${ }^{3}$ English Department, Najafabad Branch, Islamic Azad University, Najafabad, Iran \\ E-mail address: r.shirazi90@yahoo.com, a.hesabi11@yahoo.com \\ shahlasimin@yahoo.com
}

Keywords: pedagogical English movies, Persian subtitle, L2 vocabulary learning

\begin{abstract}
Throughout the history of language teaching, using subtitles has had their particular advocates in teaching English as a second language. This study was conducted to investigate the impacts of Persian subtitled movies on vocabulary knowledge improvement of Iranian intermediate EFL learners. To achieve this goal, out of 35 participants, 20 female learners from a language institute in Isfahan, took part in the study. Their ages were between 12 to 16 years old and they were randomly divided into two homogenous groups (controllable and uncontrollable subtitle groups) based on Oxford Placement Test (OPT). As the pretest of the study, a content specific vocabulary test was administered which consisted of 30 multiple-choice items and was developed by the present researchers. Instructional materials included 10 parts of a movie, titled 'Tangled' (produced in 2010). During 10 sessions of treatment, vocabularies were instructed to the participants. Experimental group was instructed watching a controllable subtitled movie (English dialogues with repeated Persian subtitles) while control group was instructed using the same audiovisual materials but without any repetition; watching an uncontrollable subtitled movie (English dialogues with unrepeated Persian subtitles). After treatment, as the posttest, the two groups were administered a test similar to the pretest and under the same conditions. Based on the findings of analysis of covariance on the pretest and posttest vocabulary test scores, the results indicated that the group using controllable Persian subtitles outperformed than the other group. Material designers and instructors can use the findings of this investigation to include movies with Persian subtitles for learners to learn more vocabulary due to the fact that these learners have learnt to appreciate the importance and the value of vocabulary, including its effectiveness in communicative tasks.
\end{abstract}

\section{INTRODUCTION}

Technology cannot be separated from classroom environment; therefore, different stakeholders bring relevant technologies to their teaching and learning situations. Recently, movies are one of the visual aids that is used increasingly as a way to highlight communicative aspect of language learning. According to Hemei (1997), movies are considered as rich and important resources which are preferred by both L2 learners and teachers. The L2 learners enjoy watching movies due to the fact that these visual materials are motivating, demanding, and interesting to watch. The L2 learners rely more heavily on visual clues to help their understanding, and certainly movie is an obvious medium for helping learners to interpret the visual clues effectively. Movies present the behavior of people whose language is being learned by the L2 learners along with a wide range of communicative situations. According to Allan (1985), positive effects of pedagogical movies on learners' attention could improve their language ability. Moreover, using movie for L2 teachers is convenience because it promotes comprehension. The L2 teachers use pedagogical movies for advanced and less advanced learners. However, the pedagpgical movie which is illustrated to less advanced learners needs to be shorter because of limited language knowledge. Moreover, in this issue Arthur (1999) claims that movie can give students realistic models to imitate 
for role-play; can increase awareness of other cultures by teaching appropriateness and suitability. Language teachers like pedagogical movie because it motivates learners, brings the real world into the classroom, contextualizes language naturally and enables learners to experience authentic language in a controlled environment.

Neves (2008) believed that addressees of subtitles are not a special or unique group; so, different age groups and social backgrounds should be considered in subtitling. L1 subtitles are used to translate foreign language dialog into the native language of the learners. It is the cheapest and quickest method of content translation; moreover, it is preferred because audience can hear the original voices and dialog of the actors. Subtitling may give information that would otherwise be difficult to provide from hearing (Harji, Woods, \& Kamal Alavi ,2010). Therefore, watching subtitled movies and programs can lead to learning a foreign language in and out of classroom. (Zarei, Rahmany, \& Gilanian, 2013).

A word is described as a sound or a combination of sounds, or its representation in writing or printing that symbolizes and communicates a meaning. In order to understand a word it is not enough to learn its meaning. It is necessary to learn its register, association, collocation, grammatical behavior, written form, spoken form and frequency. All these properties are known as "word knowledge" (Schmitt, 2000, p. 5). According to Zimmerman (1997, p. 17), vocabulary learning is "arguably central to language acquisition and use." One of the demanding tasks for the EFL learners is learning new vocabularies. Vocabulary plays an important role in English language learning and is considered as the basis of L2 communication.

This study investigated how pedagogical movies containing controllable standard subtitles (English dialogues with repeated Persian subtitles) can lead Iranian EFL learners to acquire easily more English vocabulary. Subtitling can also develop for learners the influence sphere of vocabulary and help them to connect the verbal form of the language with the written form and to promote speaking skill and pronunciation. Perhaps, the EFL learners who are exposed to watching pedagogical movies with controllable standard subtitles find it more helpful because they have the opportunity to reiterate several times the vocabularies have not been recognized during viewing the movies. The purpose of this study is to find out which one, English pedagogical movies with repeated or unrepeated Persian subtitles, can help EFL learners improve their L2 vocabulary learning.

\section{REVIEW OF THE RELATED LITERATURE}

Paivio (1971) suggests the dual- coding theory, in which he claims when we add pictures to the meaning, the quantity of signals which is connected to the message increases. Therefore, it is more probable that the messages be kept in the viewers' mind. The results show that interaction with video, audio and multi-sensory processing and print mechanisms will be activated due to the use of subtitles.

It was revealed that movies are valuable teaching material to be used in EFL classrooms because they are capable of providing a rich source of context and vocabulary for the EFL learners. Reese (1987) declares that visual illustrations can be more effective if they are along with script. One of the significant aspects of technology that assists in stimulating and facilitating language learning is audio-visual materials (Çakir, 2006). In their investigation Borras \& Lafayette (1994) incorporated subtitles into short video segments that were integrated into an interactive multimedia course. The participants were able to see and control a video segment with or without same language subtitles. Results showed that having the opportunity to see and control subtitles positively influences both comprehension and production of language.

According to some scholars (e.g., Garza, 1991; Paivio, 1971; Krashen, 1983; Stewart and Pertusa, 2004 and Vanderplank, 1988), subtitling can increase the target language knowledge of the learners by using new phrases and lexicons in a proper context. Meskill (1996) believed that subtitled movie, a combination of pictures, sounds, and texts, do not hinder comprehension, but rather enhance it. Subtitles along with the movies have lots of distinct advantages. The first one is that learners recognize that subtitles are helpful (Chung \& Hsin, 1999; Taylor, 2005). 
Katchen (1997) conducted an empirical research about what instructional issues may teachers involve when they apply L1 subtitles with second language TV recordings in L2 classes. The experimental group was 14 native Chinese speakers who attended in an advanced English listening class. The research focused on the issues and questions which could be involved when the EFL learners in intermediate-to-advanced levels encounter to both written Chinese and spoken English. The results showed that learners get benefits from vocabulary, phrases and slang in foreign language movies containing L1 subtitles. The finding also revealed that the learners who had good listening skills recognized that their progress was slowed due to subtitles, but they were beneficial too. Lower learners in listening skills were more dependent on subtitles. Vanderplank (1988) conducted a research on high-intermediate adult learners of Europe. It was reported that the participants felt they could be relax when they were listening to the movie's auditory track because the presence of the subtitles made learners assure about their checking the vocabulary they heard if they needed to (Chiang, 2006).

Linebarger (2001) investigated about the sound, subtitle use and the reading behavior of the participants who were children in the second grade. The result of this experiment revealed that beginners who watch movies with subtitles could identify more words in their readings. The conclusion was that children are helped by the combination of sound and subtitle to recognize the critical story elements especially the keywords in the movies. According to Danan (2004) it is recommended that stakeholders facilitate subtitling in spite of the fact that some researchers believe these technologies are distracting and may lead to listening laziness. Zanon (2006) states that the learners will be motivated when they watch subtitled movies and their language learning and comprehension improve considerably since it is a pleasurable and nice activity. They get familiar with the target culture and they also acquire correct pronunciation. Subtitling has a remarkable role in new vocabulary and idioms.

According to Kim and Gilman (2008), L2 learners used to acquire the new vocabulary along with their translations in a list form. But, these strategies are found to be outdated, and they are not suitable for those L2 learners who prefer visual stimuli. Bianchi and Ciabattoni (2008) explored about the subtitled movies' effect on different proficiency levels of the learners. In their research, beginners improved to a higher degree by L1 subtitles, while the learners in the more advanced levels gained advantage mostly from L2 subtitles. Hayati \& Mohammadi (2009) state that movies with Persian subtitles facilitate English vocabulary learning by providing the meaning of the context in the learners' native language compared to movies with no subtitles.

In sum, according to Krashen (1989), in order that learners get to the purpose of learning a second language successfully, when they learn that language, it is necessary that they be given a great amount of comprehensible input. Using subtitled movies and their useful impacts in vocabulary learning of L2 learners have been supported by most of the researchers (Etemadi, 2012). However, it seems to be a lack of research on the impact of watching pedagogical movies with controllable and uncontrollable subtitles on vocabulary improvement of Iranian EFL learners. Therefore, this study can be seen as a contribution to fill the gap. In this light, the following question is addressed in this study:

- Is there any significant difference between vocabulary learning of Iranian EFL learners who view pedagogical movies with controllable Persian subtitles and those who view them with uncontrollable Persian subtitles?

\section{METHODOLOGY}

\subsection{Participants}

Participants of the current study were 20 female learners in the intermediate level who were selected from a population of 35 EFL learners with the age range of 12 to 16 . The participants were studying English for almost six terms in Paya English institute in Isfahan, Iran. Participants randomly assigned to two groups in the treatment. The groups are introduced as follows: Experimental group who viewed the English pedagogical movie containing controllable Persian 
subtitle and control group who viewed the same English pedagogical movie with uncontrollable Persian subtitle.

\subsection{Instruments}

In order to identify the impact of English pedagogical movie and use of controllable and uncontrollable Persian subtitles on vocabulary knowledge of the learners who had viewed the movie, two instruments; a placement and a vocabulary test were administered during the study to the participants of the two groups. The Oxford Placement Test (OPT) was administered to select two homogeneous groups of participants in terms of language proficiency. It should be noted that the validity and reliability of this test had already been established. The vocabulary test contained 30 multiple-choice items and was designed by the present researchers to test the extent to which the participants know the meanings of the L2 vocabulary in the movie; the learners were supposed to answer them in 15 minutes. This vocabulary test was used as the pretest and posttest of the study. The vocabulary post-test was administered at the end of the 10th sessions in each multimedia English class and the results were compared to know the effect of watching repeated Persian subtitled movie versus unrepeated Persian subtitled one on the learners' vocabulary learning. The reliability of the vocabulary test was estimated using Cronbach alpha. Moreover, its validity was verified by factor analysis and the expert judgments.

\subsection{Procedure}

This study was conducted in 10 sessions of instruction, during 4 weeks, in Paya institute in Isfahan. The first step was to make sure of the learners' homogeneity. Then the participants were randomly divided in two groups. In the second step, to measure the English background knowledge of participants, at the outset of the term a researcher-made vocabulary test containing 30 multiple choice items, as the pretest, was given to the participants. It had been piloted to ensure that the participants did not know the target words in the movie so as to have a common base for the comparison of the two groups. The participants were supposed to choose the correct word among the four alternatives. The allotted time was 15 minutes. It should be noted that the validity and reliability of this test had already been established. In the third step, the participants in the two groups viewed a movie (named 'Tangled', which was released by Disney Picture in 2010). The control group was required to watch the pedagogical movie with uncontrollable Persian subtitle while the experimental group was required to watch the same movie with controllable Persian subtitle. During the treatment, participants were engaged in different classroom tasks/activities to do the exercises and the teacher asked some questions forcing the learners to use new vocabularies to answer. In the second class with the Persian controlled subtitles, caption-on and caption-off activities were done so that the participants could practice the content-based vocabularies. In the fourth step, at the end of the experiment, in order to evaluate the findings of the study and to know the importance of repetition of the movie subtitles, the same multiple-choice vocabulary test in which the items were reordered, as the posttest, was administered. Finally, analysis of covariance (ANOVA), an extension to repeated-measured ANOVA, was run through SPSS to show the main effects of the group difference (independent variable) in the current study.

\section{RESULTS}

The research question of this study examined the difference between vocabulary knowledge improvement of Iranian EFL learners who viewed English pedagogical movies with controllable (repeated) Persian subtitle and those with uncontrollable (unrepeated) Persian subtitle. To address this question a one-way ANCOVA was conducted. Before calculating the analysis of covariance, initial analyses were performed to ensure no violation of the assumptions of normality, linearity, homogeneity of variances, homogeneity of regression slopes. The results showed no serious violations of the assumptions. The descriptive data of learners' vocabulary scores with respect to the two controllable Persian subtitle (CPS) and uncontrollable Persian subtitle (UPS) groups are demonstrated in Table 1. 
Table 1

Descriptive Statistics of the two Subtitle Groups (CPS and UPS)

\begin{tabular}{llcccccc} 
& & $\mathrm{N}$ & Mean & Std. Deviation & Std. Error & Minimum & Maximum \\
\hline Pretest & UPS & 12 & 7.71 & 3.791 & 1.013 & 4 & 14 \\
& CPS & 14 & 11.50 & 3.000 & .866 & 8 & 15 \\
& Total & 26 & 9.46 & 3.891 & .763 & 4 & 15 \\
\hline Posttest & UPS & 12 & 10.57 & 2.472 & .661 & 8 & 15 \\
& CPS & 14 & 13.83 & 2.082 & .601 & 10 & 16 \\
& Total & 26 & 12.08 & 2.799 & .549 & 8 & 16 \\
\hline
\end{tabular}

Table 1 shows that, regarding the pretest scores, the mean of the UPS group $(M=7.71)$ is smaller than the mean score of the CPS group $(\mathrm{M}=11.50)$. Likewise, concerning the posttests, subjects in the CPS group outperformed those in the UPS group (see Figure 1).

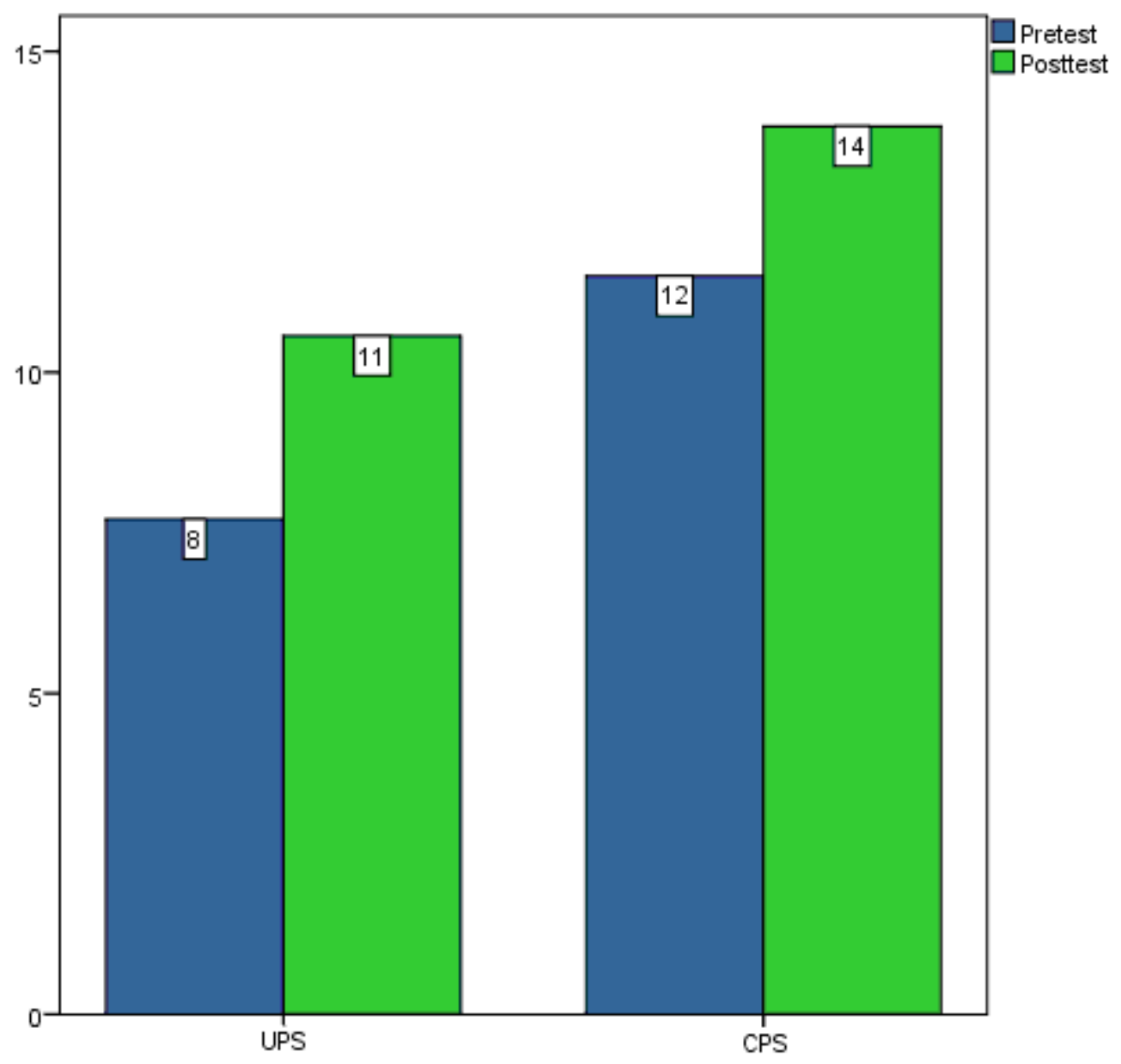

Figure 1. Bar graph of pretest and posttest scores in the CPS and UPS groups

Although the posttest mean score of the two groups are different, it is not clear whether these discrepancies are due to the differences in the pretests. Thus, adjusted means of posttests, reported in Table 2, should be checked. 
Table 2

Descriptive Statistics of Adjusted Mean Scores of the Posttests in the Two Groups

\begin{tabular}{lcccc}
\hline & & & \multicolumn{2}{c}{$95 \%$ Confidence Interval } \\
\cline { 3 - 5 } & & Std. & Lower & Upper \\
Group & Mean & Error & Bound & Bound \\
\hline UPS & $11.12^{\mathrm{a}}$ & .595 & 9.886 & 12.348 \\
CPS & $13.20^{\mathrm{a}}$ & .650 & 11.853 & 14.541 \\
\hline
\end{tabular}

a. Covariates appearing in the model are evaluated at the following values: Pretest $=9.46$.

Table 2 reveals that while pretest scores are hold constant, the mean score of learner's who watched movies with controllable subtitles $(\mathrm{M}=13.20)$ is larger than the mean score of the other group $(\mathrm{M}=11.12)$.

Table 3

One-way ANCOVA for Group Effect on the Vocabulary Scores

\begin{tabular}{|c|c|c|c|c|c|c|}
\hline Source & $\begin{array}{l}\text { Type III Sum } \\
\text { of Squares }\end{array}$ & $\mathrm{df}$ & Mean Square & $\mathrm{F}$ & Sig. & $\begin{array}{l}\text { Partial Eta } \\
\text { Squared }\end{array}$ \\
\hline Corrected Model & $96.639^{\mathrm{a}}$ & 2 & 48.319 & 11.202 & .000 & .493 \\
\hline Intercept & 234.175 & 1 & 234.175 & 54.290 & .000 & .702 \\
\hline Pretest & 27.888 & 1 & 27.888 & 6.465 & .018 & .219 \\
\hline Group & 21.104 & 1 & 21.104 & 4.893 & .037 & .175 \\
\hline Error & 99.207 & 23 & 4.313 & & & \\
\hline Total & 3988.000 & 26 & & & & \\
\hline Corrected Total & 195.846 & 25 & & & & \\
\hline
\end{tabular}

a. $\mathrm{R}$ Squared $=.493$ (Adjusted R Squared $=.449$ )

The results of the ANCOVA, illustrated in Table 3, indicated that there is a statistically significant difference between the CPS and UPS group regarding the vocabulary scores, $F=4.89, p$ $<.05$. Therefore, the students' vocabulary knowledge improved significantly in the CPS group i.e., those who watched movies with controllable Persian subtitles. Based on the observed results, it can be concluded that the implementation of controllable Persian subtitles led to more vocabulary improvement than did the application of uncontrollable Persian subtitles.

\section{DISCUSSION}

This research set out to explore how Iranian English learners deal with learning English vocabulary through viewing controllable (repeated) or uncontrollable (unrepeated) Persian subtitled movies in English classes. In response to the research question, by presenting controllable or uncontrollable Persian subtitled movies to two groups of English learners the researchers captured that controllable Persian subtitled movie aid learners to improve their vocabulary knowledge more easily and more effectively than uncontrollable Persian subtitled one. Controllable L1 subtitles also help learners in overall comprehension of the English movie texts. In line with the present study, the advantage of watching English movies containing L1 subtitles on L2 learners' vocabulary improvement is supported by plethora of studies, such as Katchen (1997) who conducted an empirical research about L1 subtitling. His findings revealed that learners get benefits from vocabulary, phrases and slang in foreign language movies containing L1 subtitles. He also concluded that lower participants in listening skills were more dependent on subtitles. Bravo (2005) stated that language learning is the result of both native and target language subtitles. He argues that L1 subtitles are suitable for low-level proficiency learners, whereas advanced students take a lot of 
advantages from the target language (L2) subtitles in developing pronunciation and the knowledge of vocabulary, and idioms.

Furthermore, the results of the current research are in line with the studies conducted by Guillory (1998), Chiang (2006), Hayati and Mohammadi (2009), and Wang and Shen (2008) who reported that the group using controllable L1 subtitle performed significantly better on vocabulary learning compared to uncontrollable L1 subtitle group. The above findings of the present research are in line with the studies conducted by (Garza, 1991; Goldman, 1996; Neuman \& Koskinen, 1992; Price, 1983; Vanderplank, 1988; Goldman \& Goldman, 1988; Koskinen, Wilson, \& Jensema, 1985) who believed that controllable subtitling served learners to the function of drawing their attention to learning vocabulary of the movie. They concluded that controllable subtitling had significant impact on learners' L2 skills. Nonetheless, some claims made by several researchers can challenge the findings of the present study. For instance, Bianchi and Ciabattoni (2008) believe that regarding vocabulary comprehension, L1 subtitles are more advantageous than L2 subtitles, especially for the novice learners. The beginners improve to a higher degree by L1 subtitles. Based on the cognitive theory of multimedia learning, in the learning process interactive role of the learners can boost learning because it can reduce the possibilities of cognitive overload. Therefore, when the presentation rate control of explanations of multimedia is on the hand of the learners, meaningful learning happens (Mayer, 2002). Markham (1999) investigated the effect of subtitles on aural word recognition skills and found that the availability of subtitles, when they subsequently heard them again, significantly improved the participants' ability to identify the key words (p: 323-4). Moreover, Moreno and Mayer (2007) argue that utilizing subtitled movies is not useful in L2 classroom because the subtitling in movies can overload the visual channel by presenting visuals, texts, and verbal data at the same time in learners' working memory; hence, this issue can reduce meaningful learning.

According to the results of the study, in pretest and posttest, the mean of the two groups of participants was significantly different. It indicated that for improving English vocabulary the Persian English participants outperformed with controllable (repeated) Persian subtitled movie. EFL learners who viewed an English pedagogical movie with controllable English subtitles benefit because they find the opportunity to repeat many times the vocabularies that they have not noticed during viewing the movie.

\section{CONCLUSION AND IMPLICATIONS}

The main aim of English pedagogical movie subtitles as a language learning tool is to prepare students to understand actual speech in order to communicate in real situations. The presence of controllable or repeated subtitles of the movie ensures Iranian language learners that not a single word from the dialogues will be missed. Based on the results of the previous researches and the present study we come to the conclusion that Persian subtitles, in general, and controllable Persian subtitlles, in particular, have a significant role in improving Iranian foreign language learners' vocabulary knowledge. The research findings revealed that most of the participants had positive attitudes toward viewing movies with controllable i.e, repeated, Persian subtitles (CPS). The results indicated that using movies with controllable Persian subtitles is a better way to help students to improve the vocabulary knowledge compared to the movies with uncontrollable Persian subtitles.

While watching movies, learners might encounter processing difficulties such as matching between reading the subtitles and listening the dialogues of the movie speakers. Instructors and teachers can help learners by diagnosing these problems and providing more input for them. Therefore, learners would be able to listen and practice various segments or episodes of the movie and their vocabularies, several times.

Furthermore, the findings of the current research show that, unlike boring traditional methods of teaching vocabulary, using audiovisual techniques such as movie L1 subtitles as a means for the explicit teaching of L2 vocabulary can be useful and crucial in promoting target language skill and subskills of the learners and improving their vocabulary knowledge. By 
implications, syllabus designers and materials developers can adapt vocabulary exercises in L2 instructional materials by considering the use of multimedia and subtitled pedagogical movies in L2 classes. L2 learners can benefit from engaging in movie-watching as an aid for learning new vocabulary in a stress-free environment; they should be explicitly encouraged to pay attention to the L2 subtitles and make necessary pauses for taking notes or rewinding.

\section{References}

[1] Allan, M. (1985). Teaching English with video. London: Longman.

[2] Arthur, P. (1999). Why use video? A teacher's perspective. VSELT, 2(4), 4-18.

[3] Bianchi, F.,\& Ciabattoni, T. (2008). Captions and subtitles in EFL learning: An investigative study in a comprehensive computer environment. In A. Baldry, M. Pavesi, \& C. Taylor Torsello (Eds.), From didactas to ecolingua.

[4] Borras, I., \& R.G. Lafayette. (1994). Effects of multimedia courseware subtitling on the speaking performance of college students of French. The Modern Language Journal, 78(1), 6675.

[5] Bravo, M. C. (2005). Foreign language learning made simpler by reading subtitles? Studies in teacher education; language, literature, and culture. Edited by Misztal, M. \& Trawinski, M. 105-114.

[6] Çakır, İ. (2006). The use of video as an audio-visual material in foreign language teaching classroom. The Turkish Online Journal of Educational Technology- TOJET, 5(4), article 9.

[7] Chiang. Y. R. (2006). A Comparative Study of Different Subtitling Formats in Two English News Broadcast in Taiwan. MA thesis. Taiwan: National Tsing Hua University.

[8] Chung, J. \& Hsin, M. (1999). The effects of using video texts supported with advance organizers and captions on Chinese college students' listening comprehension: An empirical study. Foreign Language Annals, 32 (3), 295-305.

[9] Danan, M. (2004). Captioning and subtitling: Undervalued language learning strategies. Meta, 49(1), 67-77.

[10]Etemadi, A. (2012). Effects of bimodal subtitling of English movies on content comprehension and vocabulary recognition. International journal of English 1 inguistics, 2(1), 239-248.

[11]Garza, T. J. (1991). Evaluating the use of captioned video materials in advanced foreign language learning. Foreign Language Annuals, 24(3), 239-258.

[12] Goldman, M. (1996). If you can read this, thank TV. TESOL Journal, 6(2), 15-18.

[13] Goldman, M., \& Goldman, S. (1988). Reading with closed-captioned TV. Journal of Reading, $31,458-461$.

[14] Guillory, H.G. (1998). The effects of keyword captions to authentic French video on learner comprehension. CALICO Journal 15(1), 89-108.

[15]Harji, B. M., Woods, C. P., \& Alavi, Z. K. (2010). The effect of viewing subtitled videos on vocabulary learning. Journal of College Teaching \& Learning, 7(9), 37-42.

[16] Hayati, A. \& Mohammadi, F. (2009). The effect of films with and without subtitles on listening comprehension of EFL learners. British Journal of Educational Technology, 4 
[17]Hemei, J. (1997). Teaching with videos in an English class. Journal of English Teaching Forum, 35(2), 45-56. 2(1), 181-192.

[18]Katchen, J. (1997). Can students learn English from the X-Files? In J.E. Katchen \& Y.N. Leung (Eds.), The proceedings of the fifth of international symposium in English teaching. Taipei: The Crane Publishing Company, Ltd.

[19]Kim, D. \& Gilman, D. A. (2008). Effects of Text, Audio, and Graphic Aids in Multimedia Instruction for Vocabulary Learning. Educational Technology \& Society,11(3),114-126.

[20]Koskinen, P., Wilson, R., Jensema, C. (1985). Closed-captioned television: A new tool for reading instruction. Reading World, 24, 1-7.

[21]Krashen, S. (1983). The natural approach. San Francisco: Alemany Press.

[22] Krashen, S. (1989). We acquire vocabulary and spelling by reading: Additional evidence for the input hypothesis. The modern language journal, 73, 440-464.

[23]Linebarger, L. D. (2001). Learning to Read from Television: The Effects of Using Captions and Narration. Journal of Educational Psychology, 93 (2), 288-98.

[24]Markham, P. (1999). Captioned videotapes and second language listening word recognition.Foreign Language Annals, 32, 321-328.

[25] Mayer, R. E. (2002). Multimedia learning [Abstract]. Psychology of Learning and Motivation, 41, 85-139.

[26]Meskill, C. (1996). Listening skills development through multimedia. Jl. of Educational Multimedia and Hypermedia, 5(2), 179-201.

[27]Moreno, R., \& Mayer, R. E. (2007). Interactive multimodal learning environments. Educational Psychology Review, 19 (3), 309- 326.

[28]Neuman, S. B., \& Koskinen, P. (1992). Captioned television as comprehensible input: Effects of incidental word learning from context for language minority students. Reading Research Quarterly, 27(1), 95-106.

[29]Neves, J. (2008). 10 fallacies about subtitling for the d/Deaf and the hard of hearing. The journal of specialized translation, 10.

[30]Paivio, A. (1971). Imagery and cognitive process. New York: Holt, Rinehart \& Winston.

[31]Price, K. (1983). Closed-captioned TV: An untapped resource. MATSOL Newsletter, 12, 78.

[32]Reese, S. (1987). Visual-verbal redundancy effects on television news learning. Journal of Broadcasting \& Electronic Media, 28, 79-87.

[33] Schmitt, N. (2000). Vocabulary in language teaching. Cambridge University Press.

[34] Stewart, M., \& Pertusa, I. (2004). Gains to language learners from viewing target language closed- captioned films. Foreign Language Annals, 37(3), 438-447.

[35] Taylor, 1. (2005). Consideration of choosing an English-English dictionary for ESL students.

[36] Vanderplank, R. (1988). The value of teIetext sub-titles in language learning. ELT Journal, 42(4), 272-28 1. 
[37]Wang, Y.,\& Shen, C. (2008). Tentative model of integrating authentic captioned video to facilitate ESL learning. Sino-Us English Teaching, 4(9), 1-13.

[38]Zanon, N. T. (2006). Using subtitles to enhance foreign language learning. Porta Linguarum, 6, 41-52. students.

[39]Zarei, A. A., Rahmany, R., \& Gilanian, M. (2013). Multimedia input modality affecting L2 vocabulary learning. Germany: Lambert Academic Publishers.

[40]Zimmerman, C. B. (1997). Do reading and interactive vocabulary instruction make a difference? An empirical study. TESOL Quarterly 31(1), 121-138. 